\title{
Computational analysis of the lean-burn direct- injection jet ignition hydrogen engine
}

\author{
A Boretti ${ }^{1 *}, \mathrm{H}$ Watson ${ }^{1}$, and A Tempia ${ }^{2}$ \\ 'School of Science and Engineering, University of Ballarat, Ballarat, Victoria, Auatralia \\ ${ }^{2}$ Robert Bosch (Australia), Pty Ltd, Clayton, Victoria, Australia \\ The manuscript was received on 28 May 2009 and was accepted after revision for publication on 6 Augus 2009. \\ DOI: $10.1243 / 09544070$ AUTO1278
}

\begin{abstract}
This paper presents a new in-cylinder mixture preparation and ignition system for various gaseous fuels including hydrogen. The system consists of a centrally located directinjection (DI) injector and a jet ignition (J) device for combustion of the main chamber (MC) mixture. The fuel is injected in the MC with a new-generation fast-actuating high-pressure high-flowrate DI injector capable of injection shaping and multiple events. This injector produces a bulk lean stratified mixture. The $J$ system uses a second DI injector to inject a small amount of fuel in a small pre-chamber (PC). A spark plug then ignites a sightly rich mixture. The MC mixture is then bulk ignited through multiple jets of hot reacting gases. Bulk ignition and combustion of the lean jet-controlled stratified MC mixture resulting from coupling DI with $\rfloor$ makes it possible to burn MC mixtures with fuel-to-air equivalence ratios reducing almost to zero for a throttle less control of load diesel-like and high efficiencies over almost the full range of loads. Computations are performed with hydrogen as the PC and MC fuel.
\end{abstract}

Keywords: gas engines, direct injection, jet ignition, lean-burn stratified combustion, bulk ignition, combustion

\section{INTRODUCTION}

At standard temperature and pressure, hydrogen is a colourless odourless non-metallic tasteless, highly flammable diatomic gas $\mathrm{H}_{2}$. With an atomic weight of 1.00794 , hydrogen is the lightest element. Hydrogen is also the most abundant element in the universe, making up 75 per cent of normal matter by mass and over 90 per cent by number of atoms Under ordinary conditions on Earth, elemental hydrogen exists as the diatomic gas $\mathrm{H}_{2}$. However, hydrogen gas is very rare in the Earth's atmosphere because of its light weight which enables it to escape from Earth's gravity more easily than heavier gases. Hydrogen in chemically combined form is the third most abundant element on the Earth's surface. Most of the Earth's hydrogen is in the form of chemical compounds such as hydrocarbons and water.

"Correponding author: School of Sience and Enginering, University of Ballarat, PO Box 663, Ballarat, Vidoria 3353, Auatralia.

email: a_boreti@yahoo. com
Despite the fact that hydrogen can be prepared in several different ways, the economically most important processes involve removal of hydrogen from hydrocarbons. Commercial bulk hydrogen is usually produced by the steam re-forming of natural gas. Hydrocarbons other than methane can be used to produce synthesis gas with various product ratios. Other important methods for $\mathrm{H}_{2}$ production include partial oxidation of hydrocarbons Hydrogen may also be produced from water by electrolysis at substantially greater cost than production from natural gas.

Hydrogen gas is highly flammable and will burn in air at a very wide range of concentrations between $4 \mathrm{vol} / \%$ and $75 \mathrm{vol} / \%$. Hydrogen-oxygen mixtures are explosive across a wide range of proportions its autoignition temperature, the temperature at which it ignites spontaneously in air, is $858 \mathrm{~K} . \mathrm{H}_{2}$ reacts with every oxidizing element.

A hydrogen internal combustion engine $\left(\mathrm{H}_{2} \mathrm{ICE}\right)$ is a hydrogen-fuelled internal combustion engine providing efficiencies in excess of today's gasoline engines and operating relatively cleanly with nitro- 
gen oxides $\left(\mathrm{NO}_{\mathrm{x}}\right)$ being the only emission pollutant [1-3]. Table 1 (from references [1] to[ 5]) presents some properties of hydrogen to outline the unique combustion properties in internal combustion engine applications. These properties are beneficial at certain engine operating conditions and pose technical challenges at other engine operating conditions. The presented values are not all well accepted and may be sightly different in other references The definition of the research octane number (RON) in particular is open to discussion. Fgorousy, RON determination of $\mathrm{H}_{2}$ with the conventional ASTM method is not possible. The value proposed in Table 1 (from references [1], [3], and [5]) simply indicates the decrease in knock tendency of hydrogen (when surface ignition and residual gas ignition are eliminated) with reference to gasoline fue experimentally demonstrated in the limited number of engine tests performed $\mathrm{so}$ far.

Favourable properties of $\mathrm{H}_{2}$ are the wide flammability range for ultra-lean operation, the high laminar flame speed for good stability, and the high octane number for high compression ratios with improved thermal efficiency. Unfavourable properties of $\mathrm{H}_{2}$ are the high percentage stoichiometric volume fraction of the vapour with the consequent air displacement effects, the low minimum ignition energy with consequent propensity to pre-ignite, the small quenching distance for thin thermal boundary layers, and the low density that make it difficult to provide large injected mass flowrates.

Temperatures below $200 \mathrm{~K}$ are collectively known as cryogenic temperatures, and liquids at these temperatures are known ascryogenic liquids Boiling is the transition from liquid to gas. Hydrogen has the second-lowest boiling point of all substances, second only to helium. The boiling point of a pure

Table 1 Fuel properties at $25 \mathrm{uC}$ (except when otherwise noted), 1b ar, and stoichiometry (when applicable) (from references [1] to[ 5])

\begin{tabular}{|c|c|}
\hline Minimum ignition energy (MJ) & 0.02 \\
\hline 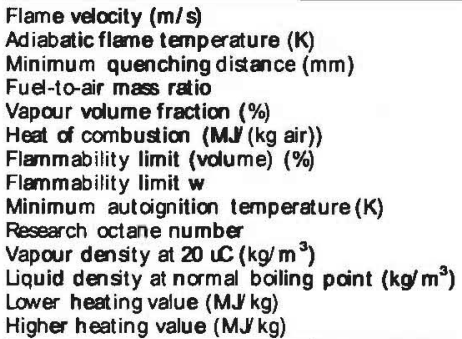 & $\begin{array}{l}1.85 \\
2480 \\
0.64 \\
0.029 \\
29.53 \\
3.48 \\
4-75 \\
0.1-7.1 \\
858 \\
120 \\
0.0838 \\
70.8 \\
119.93 \\
141.86\end{array}$ \\
\hline
\end{tabular}

substance increases with applied pressure up to a point. Unfortunately, hydrogen's boiling point can only be increased to a maximum of $33.145 \mathrm{~K}$ through the application of a pressure of $12.964 \mathrm{~b}$ ar, beyond which additional pressure has no beneficial effect.

The fuel properties play a key role in development of the direct-injection (DI) mixture preparation system. Figure 1 presents the fluid properties of methane, propane, and hydrogen along isothermal lines [6]. This picture clearly states the problems and opportunities of gas injection with variable pressure levels. Late DI overcomes the air displacement effects of port fuel injection (PFI) of gaseous fuels. However, development of a direct injector providing adequate flowrates is difficult. Propane $\left(\mathrm{C}_{3} \mathrm{H}_{8}\right)$ has a critical temperature $T_{\varepsilon} 5369.8 \mathrm{~K}$, critical pressue $p_{c} 542.5 b$ ar, and critical density $r_{\mathrm{c}} 5220.0 \mathrm{~kg} / \mathrm{m}^{3}$, while the normal boiling point is $231.1 \mathrm{~K}$. Methane $\left(\mathrm{CH}_{4}\right)$ has a critical temperature $\mathrm{T}_{6} 5190.6 \mathrm{~K}$, critical pressure $p_{c} 546.0 b$ ar, and critical density $r_{c} 5$ $162.7 \mathrm{~kg}^{3} \mathrm{~m}^{3}$ while the normal boiling point is 111.7K. Hydrogen $\left(\mathrm{H}_{2}\right)$ has a critical temperature $T_{c} 533.1 \mathrm{~K}$, critical pressure $p_{c} 513.0 \mathrm{~b}$ ar, and critical density $r_{c} 531.3 \mathrm{k} \mathrm{g} / \mathrm{m}^{3}$ while the normal boiling point is $20.4 \mathrm{~K}$. At a temperature T $5300 \mathrm{~K}$, propane is a vapour for pressures below $10.0 \mathrm{~b}$ ar, and liquid above. Conversely, methane is a vapour for pressures below $48.4 b$ ar, and supercritical above. Hydrogen is

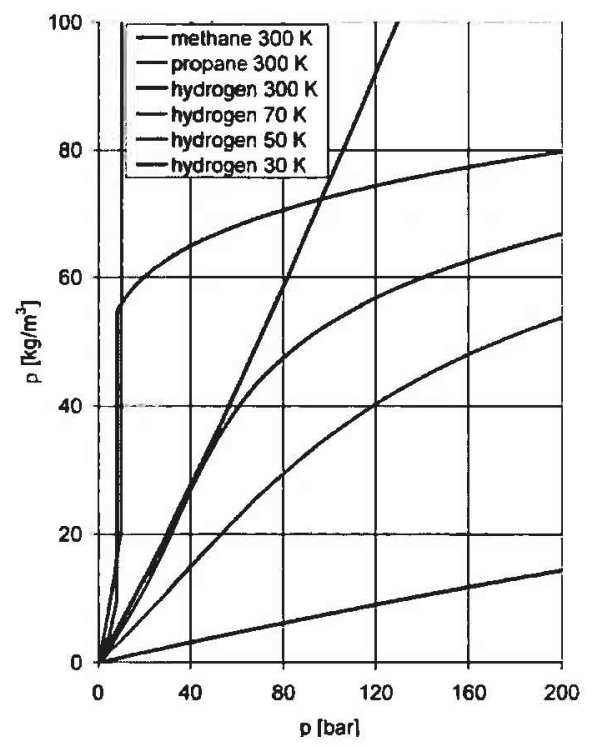

Fig. 1 Isothermal density data of propane, methane, and hydrogen [6] 
a vapour for pressures below $13.5 \mathrm{~b}$ ar, and supercritical above. Therefore, while a dedicated liquefied petroleum gas (LPG) engine may inject fuel in the liquid phase, a flexi-fuel LPG-compressed natural gas (CNG) engine would have injection in the vapour-phase if at a low pressure, and in the liquid or supercritical phase if at a high pressure. If high flowrates are possible with LPG, CNG is certainly much more demanding, even if not so challenging as hydrogen. Apart from fast actuation, pressure build up in the injection line seems to be the key factor to deliver a high flowrate within short periods of time.

\section{PROPOSED ADVANCED $\mathrm{H}_{2} I$ CES}

Different design options and engine management strategies are available for advanced $\mathrm{H}_{2}$ ICES with high power density to satisfy super-ultra-low emis sion vehicle (SULEV) emissions while providing high efficiencies and regular, smooth, and stable operation over the full range of engine speed and loads [1, 2]. The recent European Union (EU) HyICE project 'Optimization of a hydrogen powered internal combustion engine' [7] has shown cryogenic PFI and DI to be the best options currently available to develop $\mathrm{H}_{2}$ ICEs. HyICE developed and tested two concepts of mixture formation for specific hydrogen engines, $\mathrm{DI}$ at $10-200 \mathrm{~b}$ ar and cryogenic PFI at about $2200 \mathrm{uC}$. In both methods the performance was doubled while consumption was reduced with reference to prior state-of-the-art hydrogen combus tion engines designed for both gasoline and hydrogen usage. DI is also being used in the ongoing EU NICE project 'New integrated combustion system for future passenger car engines' [8] as the best option for gas engines Hydrogen-assisted jet ignition (HAJ) devices have been designed, built, and tested at the University of Melbourne over more than adecade for enhanced combustion of homogeneous lean mixtures in single and multiple-cylinder research engines [5, 9-17]. Some of the options for advanced $\mathrm{H}_{2}$ ICES are now presented and reviewed.

SULEV operation may or may not require after treatment depending on the fuel-to-air equivalence ratio w Operation at stoichiometry (w5 1) requires after-treatment with fuel-rich reduction catalyst. Lean operation ( $w<0.7$ ) requires a lean- $\mathrm{NO}_{x}$ trap (LNT). Operation in the ultralean region $(w, 0.45)$ and below does not require after-treatment.

Hydrogen engines can be run stoichiometric to the ultra-lean $(w, 0.45)$ region with very high rates of combustion. Backfiring (or back flashing) and preignition are major problems especially at stoichio- metry, and knock may limit spark advances up to ultra-lean operation and beyond. Backfiring, preignition, and knock also depend on additional factors, including the combustion chamber surface materials, surface temperature, compression ratio, pressure boosting, charge cooling, and recirculation of exhaust gases The power density, rate of combustion, and stability decrease by reducing the fuelto-air equivalence ratio, while the efficiency at first increases and then decreases going towards leaner operation.

The combustion rate deteriorates moving from ultra-lean combustion $(w, 0.45)$ to further ultra-lean combustion ( $w<0.2$ ). Moreover, ultra-lean combustion requires stratified charge with $\mathrm{DI}$ or jet ignition (d) to ensure stability. High compression ratios and pressure boosting may help to keep the rate of combustion high.

The load can be reduced by lowering the fuel-toair equivalence ratio rather than by throttling for better thermal efficiencies through the reduction in pumping losses However, the rate of combustion decreases and stability worsens when the fuel-to-air equivalence ratio is reduced and, after certain values of fuel-to-air equivalence ratios, the efficiency drops significantly.

Conventional PFI engines with gaseous fuel are the most susceptible to pre-ignition and knock. This 'warm' PFI also has the disadvantage that the large displacement of air (stoichiometric volume fraction, 29.53 per cent) limits the air-based volumetric efficiency and ther efore the power output. Cryogenic PFI with the embedded charge cooling significantly reduces displacement effects and sensitivity to knock and pre-ignition and dramatically improves the volumetric efficiency.

DI of gas-phase $H_{2}$ is also less susceptible to preignition, produces reduced or even no displacement effects, and eliminates back flash. Displacement effects with early DI are not too far from those of $\mathrm{PFI}$, while late DI may almost cancel these effects. DI enables stratified operation with the engine able to run in a more ultra-lean way for lower $\mathrm{NO}_{x}$ emission and higher efficiency. DI also considerably improves the fuel economy at part-load, mainly because of reduced pumping losses. Late DI has the penalty of needing to deliver $\mathrm{H}_{2}$ at a pressure of $100 \mathrm{~b}$ ar or more with consequent fuel pressurization work, which is less for cryogenic $\mathrm{H}_{2}$.

The power density may be increased by introducing pressure boosting, supercharging or turbocharging. However, with pressure boosting, the temperature increases, the heat transfer increases, the knock 
tendency increases, and the maximum allowable compression ratio is reduced. With the addition of an intercooler, the temperature rise across the compressor can be significantly offæet.

The rate of combustion (and therefore its stability) and the lean limit may be improved by replacing the standard spark ignition (S) in the main chamber (MC) with ignition in a pre-chamber (PC). In the HAJ system, additional fuel is injected in a PC connected to the $\mathrm{MC}$ via calibrated orifices creating fuel-rich conditions in the pre chamber. Following ignition by a conventional spark plug in the PC, the $\mathrm{MC}$ lean mixture is then ignited by the jets of hot products and radicals from the PC, enabling faster combustion of the lean MC mixture to occur. Flame speed enhancement of up to six times has been measured.

Exhaust gas recirculation (EGR) allows lean equivalent conditions with stoichiometric inflow. EGR allows after-treatment with a reduction catalyst, and the excess air is replaced by EGR dilution. EGR also mitigates pre-ignition effects in the case of warm PFI. Cool EGR controls the charge temperature within the cylinder and may also be beneficial for lean operation.

\section{THE LEAN-BURN DIRECT-INJECTION JET IGNITION $\mathrm{H}_{2}$ ICE}

MC DI of fuel with fast-actuating high-flowrate highpressure injectors capable of injection shaping and multiple events, and MC J, with ignition by spark or autoignition in a small-volume PC providing minimal complication of cylinder head design with PC mixture preparation by PC DI $[18,19]$ has never been considered before for both stationary and transport applications. In large-volume PC ignition systems for large gas engines the PC fuel is not negligible, the cylinder head design is strongly affected, and PC combustion is important also in itself and not just in initiating MC combustion whereas, in standard DI injectors, the DI injector is a traditional low-cost slow-actuating solenoid lowpressure low-flowrate injector; finally, with standard MC S coupled to DI, combustion is wall initiated with a relatively small energy supply in just one location.

The new-generation fast-actuating high-pressure high-flowrate DI injector capable of injection shaping and multiple events produces a bulk lean jetcontrolled stratified mixture. Late DI overcomes the air displacement effects of PFI of gaseous fuels
High-energy bulk ignition is then achieved by using PC J.

The proposed ignition PC is very small in size, just a few per cent of the combustion chamber volume at top dead centre (TDC) and about $1 \mathrm{~cm}^{3}$; it is designed to be fitted within the traditional spark plug thread of diameter $14 \mathrm{~m} \mathrm{~m}$. The ignition device therefore only marginally increases the level of complexity of designing a cylinder head with a standard \$park plug.

The jets of reacting gases from the ignition PC enhance the rate of combustion of the MC mixture and allow bulk ignition and combustion for reduced heat losses and faster heat release.

The coupling of $\mathrm{J}$ and $\mathrm{DI}$ technologies allows development of an engine permitting operation with overall fuel-to-air equivalence ratios reduced to almost zero, because combustion is always started in the $J P C$ provided that there is a very small amount of fuel, and the jets of hot reacting gases from the J PC may extend combustion to globally very lean MC mixtures provided that only a minimum amount of fuel is behind the $\mathrm{J}$ nozzle, thus replicating diesel-like light-load operation.

The lean-burn DI J engine uses a fuel injection and mixture ignition system consisting of the following:

(a) one MC DI fuel injector per engine cylinder;

(b) one $\rfloor$ device per engine cylinder, the latter being made of one PC connected to the MC through one or more calibrated orifices, one PC DI fuel injector, and one PC (\$ version) or one PC (autoignition version);

(c) all the ancillaries required to supply the fuel at the desired pressures by the DI injectors and to operate the DI injectors and the $\mathrm{S}$ or the autoignition PC.

The fuel injection and mixture ignition system operation is as follows.

1. One fuel is injected directly within the cylinder by an $\mathrm{MC}$ direct injector operating one single injection or multiple injections to produce a lean stratified mixture. This non-homogeneous mixture is mildly lean in an inner region surrounded by air and some residuals from the previouscycle. The extension of the inner region may be reduced in size to achieve mean chamber average mixtures ranging from slightly to extremely lean.

2. This mixture is then ignited by one or more jets of reacting gases that issue from a PC connected to the MC via calibrated orifices, sourced from the same or an alternative fuel that was injected into 
it by a direct injector and then ignited by a spark plug discharge (spark plug version).

3. Combustion which started slightly fuel rich in the very-small-volum e PC moves to the MC through one or more $J$ nozzles, with one or more jets of reacting gases bulk igniting the $\mathrm{MC}$ mixture. The jets of reacting gases enhance combustion of lean stratified mixtures within the MC through a combination thermal energy and the presence of active radical species.

With reference to homogeneous DI or PFI and MC spark ignition, non-homogeneous $D I$ and $J$ offer the following advantages

(a) much faster, more complete, much leaner combustion;

(b) less sensitivity to mixture state and composition;

(c) reduced heat losses to the MC walls.

This is because of better fuel for same chamberaveraged lean conditions, combustion in the bulk of the in-cylinder gases, heat transfer cushion of air between hot reacting gases and walls, very high ignition energy at multiple simultaneous ignition sites igniting the bulk of the in-cylinder gases, aided by large concentrations of partially oxidized combustion products initiated in the PC that accelerate the oxidation of fresh reactants.

The advantages of the system are as follows

(a) higher brake efficiency (ratio of the engine brake power to the total fuel energy) and therefore reduced brake specific fuel consumption (BFC) (ratio of the engine fuel flowrate to the brake power) for improved full load operation of stationary and transport engines;

(b) efficient combustion of variable-quality fuel mixtures from globally near stoichiometry to globally extremely lean for load control mostly throttleless by the quantity of fuel injected for improved part-load operation of non-stationary engines

(c) opportunity in the ultralean mode to produce near-zero $\mathrm{NO}_{x}$.

\section{COMPUTATIONAL PROOF OF CONCEPT}

The concept has been applied to a $1.51 \mathrm{~S}$ fourcylinder gasoline engine with double overhead camshafts and four valves per cylinder. This engine is a V-Four 1.51 engine, with a bore of $78 \mathrm{~m} \mathrm{~m}$, a stroke of $78 \mathrm{~m} \mathrm{~m}$, an intake valve seat insert inside diameter of $32 \mathrm{~m} \mathrm{~m}$, an exhaust valve seat insert inside diameter of $26 \mathrm{~m} \mathrm{~m}$, a connecting-rod length of $109 \mathrm{~m} \mathrm{~m}$, and a pent roof combustion chamber.

While much less than $0.08 \mathrm{~m} /$ cycle has to be introduced by the PC injector, and therefore a gasoline DI injector can be used as the PC injector for prototype applications where durability and dry run capability are not an issue, a specific hydrogen injector must be developed for the short injection time, high temperature, high injection pressures, high durability, and dry run capability of the MC injector having to introduce up to $14.8 \mathrm{~m} \mathrm{~g} / \mathrm{cycle}$ and to produce the charge stratification. Lean stratified mixtures would be possible by adopting charge motion controlled by jet and shaped piston surface-wall or fully jet controlled configurations depending on the injector performance.

Figure 2 presents a view of the in-cylinder plus PC volumes, while Fig. 3 presents a sectional view with a plane passing through the $P C$ axis The $D I$ injector and the $J$ device are placed at the centre of the cylinder head. A pressure sensor for combustion studies is also located in the centre. The $J$ device is a six-nozzle type. The $\mathfrak{J}$ device is designed to fit an standard spark plug thread of diameter $14 \mathrm{~m} \mathrm{~m}$. It accommodates one racing spark plug of diameter

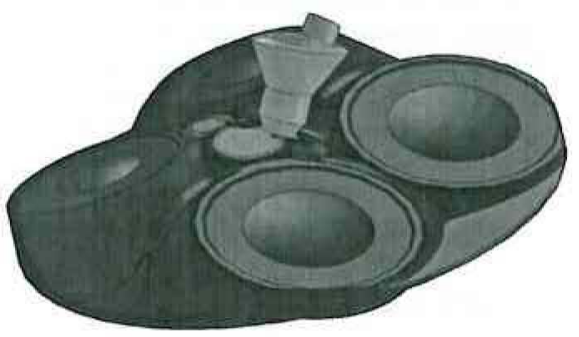

Fig. 2 View of the in-cylinder and PC volumes

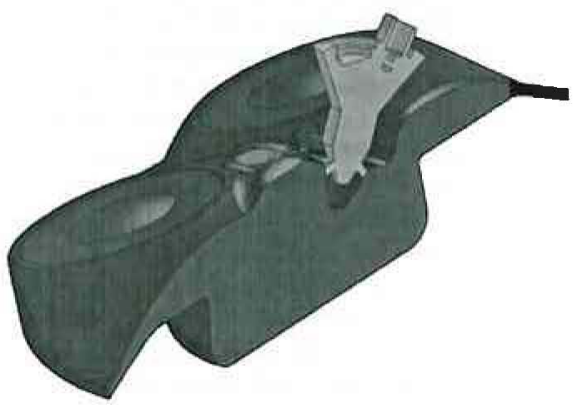

Fig. 3 Plane cut of the in-cylinder and $P C$ volumes 
$10 \mathrm{~m} \mathrm{~m} \mathrm{[20]} \mathrm{and} \mathrm{one} \mathrm{solenoid} \mathrm{gasoline} \mathrm{DI} \mathrm{injector}$ [21-23] and features six equally spaced nozzles of diameter $1.25 \mathrm{~m} \mathrm{~m}$. The $P C$ volume is $1.5 \mathrm{~cm}^{3}$. A bow-in-piston is system used to produce a lean stratified mixture. Details of the MC DI injector tip are not included.

The engine has been modelled with GT-POWER [24-28]. GT-POWER is the industry standard engine simulation tool, used by most leading engine and vehicle makers and their suppliers. Fuller details of the model have been presented in references [25] to [28]. The model has been derived from a validated high-performance engine model with PFI of gasoline [29]. The main differences are the stroke and lengths of primary intake and exhaust pipes to accommodate reduced maximum torque and power engine speeds, compression ratios, valve events, the replacing the standard spark plug, the DI injector producing lean stratified mixtures, and finaly the fuel. Compression ratios have been selected on the basis of knock index computations. The selected compression ratio produces knock index results close to those obtained for the validated highperformance engine model with PFI of gasoline. This engine turbocharged with charge cooling has a compression ratio CR of 14.5 .

The rate of combustion is computed with the predictive combustion model for stoichiometric homogeneous conditions The rate of combustion is then imposed in lean stratified operation with airto-fuel equivalence ratios I $51 /$ w\& 1 by using a Wiebe function with 50 per cent fuel burned anchored at 7.5u crank angle after TDC and 10-90 per cent combustion duration given as

$$
h_{10}{ }_{90} d \& 1, s p \frac{h_{10} 90 d-1, h p}{l^{b}}
$$

where $h_{10-00}(151, h)$ is the value computed by the predictive model for stoichiometric I 51 homogeneous combustion, $h_{10-90}(I \& 1, s)$ is the value used in the Wiebe function prescription for lean $\mid \& 1$ stratified combustion, and $b$ is a correlation coefficient smaller than unity. The rate of heat transfer is also decreased introducing a heat transfer multiplier proportional to $\mathrm{I}^{20}$ where $\mathrm{c}$ is another correlation coefficient smaller than unity. This formulation produces very fast combustion with reduced heat losses, which in turn produces very high peak pressures also running very lean, namely 90$120 \mathrm{~b}$ ar in turbocharged applications.

Results on the indicated mean effective pressure (IMEP), brake mean effective pressure (BMEP), friction mean effective pressure (FMEP), BSFC (ratio of the engine fuel flowrate to the brake power), and brake efficiency $g_{a}$ (ratio of the engine brake power to the total fuel energy), ( $g_{\mathrm{B}} ; 1 / \mathrm{BSFC}$ ) obtained during the wide-open throttle (WOT) operation are presented in Figs 4, 5, 6, 7, and 8 respectively for operation with $\mid 52,3,4$, and 5 . With $\mid 52$, the engine has a BMEP approaching $24 \mathrm{~b}$ ar at $3500 \mathrm{r} /$ $\mathrm{min}$, while the BSFC is as low as $65 \mathrm{~g} / \mathrm{kWh}$, or brake efficiencies $g_{B}$ as high as 46 per cent, approaching $3500 \mathrm{r} / \mathrm{min}$. Further improvements in brake efficiencies $g_{\mathrm{B}}$ of about 1-2 per cent are possible running slightly leaner than 152 especially in the lowengine-speed range. When load variations are obtained by varying the air-to-fuel equivalence ratio from I 52 upt o I 55 without throttling the intake, high efficiencies and low BSFCs are possible from about 25 per cent load.

Internal combustion engines generally have different $B S F C$ values at different speeds and loads. The brake efficiency $g_{a}$ is given by

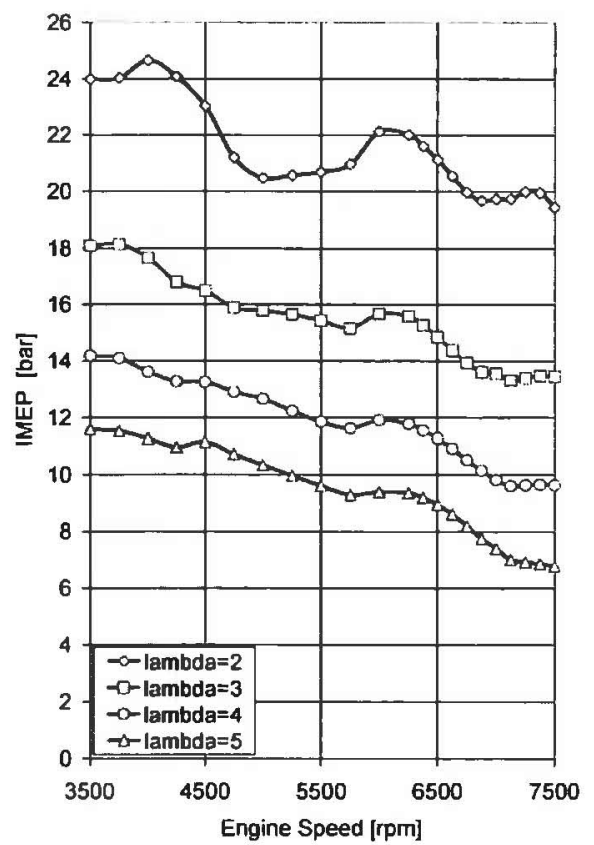

Fig. 4 IMEP results with $152,3,4$, and 5 at WOT and minimum best torque (MBT) or knock-limited spark timing 


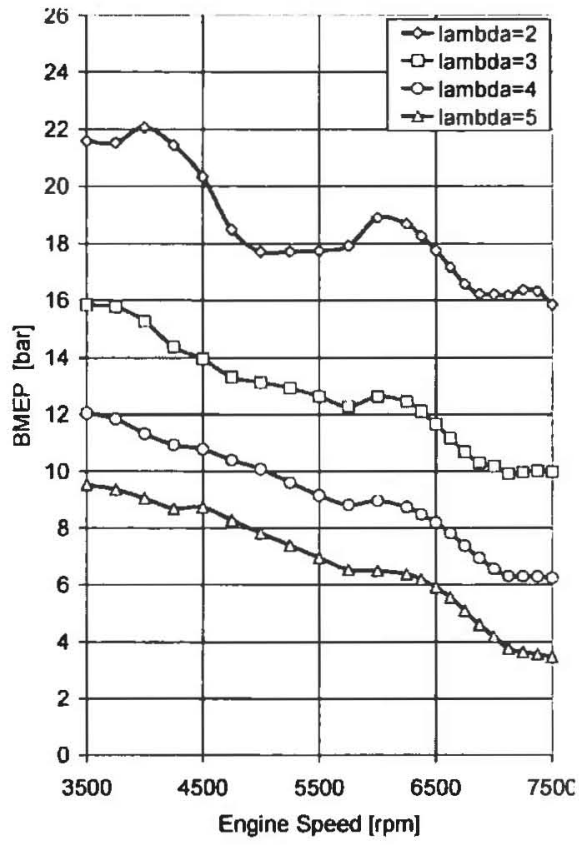

Fig. 5 BME results with I $52,3,4$, and 5 at WOT and MET or knock-limited spark timing

$$
\begin{aligned}
g_{B} & =\frac{1}{\text { BFFC }} \\
& =\frac{\text { BMEP N }}{\text { FMR }} \\
& -\frac{\text { IMEP N }}{\text { FMR }}\left\{\frac{\text { FMEP N }}{\text { FMR }}\right. \\
& =\frac{1}{\text { ISFC }} \boldsymbol{\tau} \frac{1}{\text { FSFC }}
\end{aligned}
$$

where ISFC is the indicated specific fuel consumption, FSFC is the friction specific fuel consumption, $N$ is the engine speed, and FMR is the fuel mass flowrate.

In a throttle-controlled homogeneous stoichiometric I $51 \mathrm{~S}$ gasoline engine, the minimum BSFC is usually found about peak BMEP operation with the intake not throttled. If $\mathrm{N}$ increases, the BSFC increases mostly because of the rising FMEP while, if $\mathrm{N}$ is reduced, the BSFC increases mainly because of the increased time for heat transfer to cylinder walls, reducing the IMEP, and, if the intake is throttled, the $B S F C$ increases for the larger pumping losses and therefore reduced IMEP.

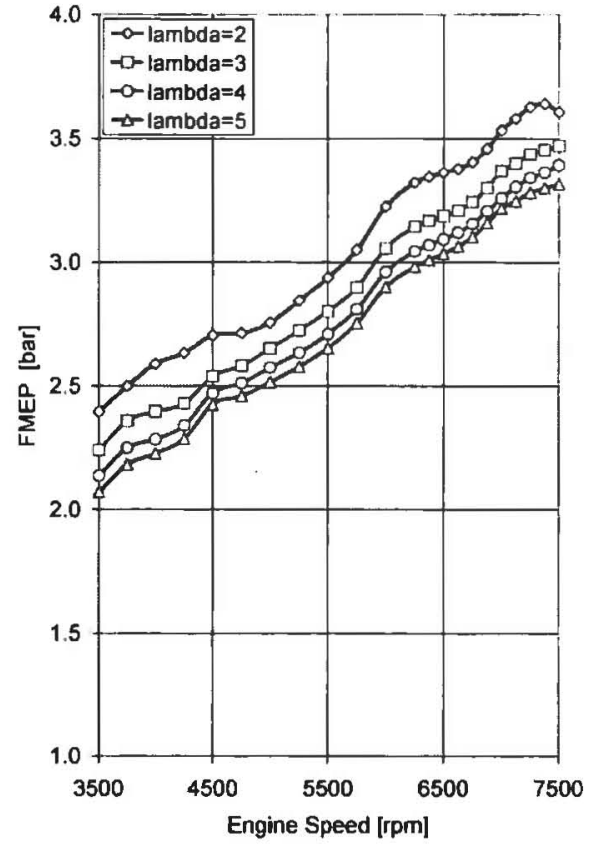

Fig. 6 FMEP results with $\mid 52,3,4$, and 5 at WOT and MBT or knock-limited spark timing

In the DI $\mathbf{l}$ engine, the fast, nearly adiabatic lean bulk combustion will deliver lower minimum BSFCs while the load control by the quantity of fuel injected will keep the BSFCs low over most of the load range, because of the improved ISFC. Increasing I generally reduces the ISFC but also increases the FSFC, as FMEP is only weakly dependent on I. Increasing I therefore reduces the BSFC only up to a minimum with I - 2; then it increases the BSFC. Increasing I, the BSFC increase running higher engine speeds becomes more relevant as the ratio FMEP/IMEP increases with increasing I.

\section{CONCLUSONS}

Coupling of $J$ and DI allows development of an engine permitting operation with overall fuel-to-air equivalence ratios that may be reduced to almost zero for diesel-like throttleless control of load and high-efficiency lean stratified bulk combustion.

The system delivers a higher brake efficiency (ratio of the engine brake power to the total fuel energy) and therefore reduced BSFC (ratio of the engine fuel 


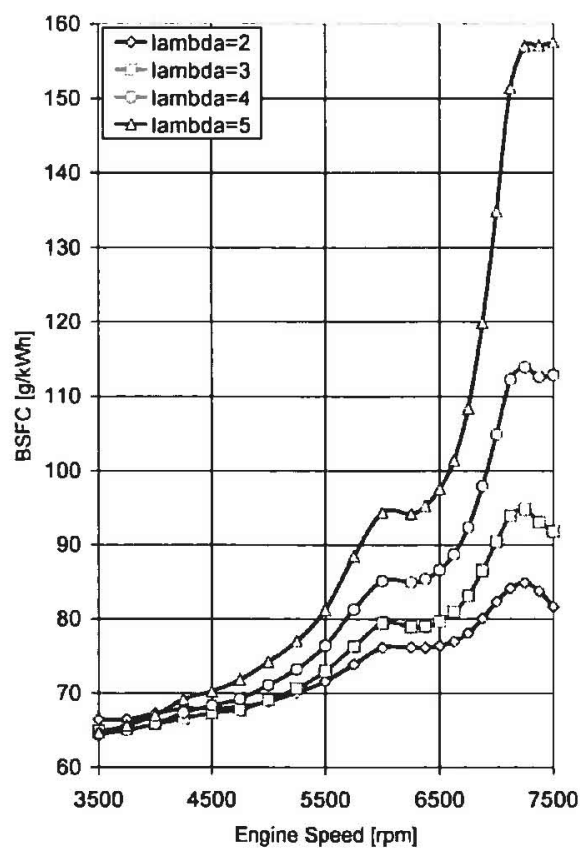

Fig. 7 BSFC results with $152,3,4$, and 5 at WOT and MBT or knock-limited spark timing

flowrate to the brake power) for improved full-load operation. The system also offers the advantage of having an efficient combustion of variable-quality fuel MC mixtures from near stoichiometry to extremely lean for improved part-load operation.

The proposed technology significantly reduces fuel energy consumption with reference to traditional throttled PFI homogeneous I 51 gasoline engines at full load and much more at part-load. Improvements are also significant when reference is made to $\mathrm{H}_{2}$ ICEs developed as a sightly modified version of the traditional gasoline internal combus tion engine burning fuel and being controlled in approximately the same manner as for gasoline engines

With reference to the two concepts developed in the $H_{y}$ ICE project, the main advantage of the technique is the load control by the quantity of fuel injected, improving the part-load operation.

The turbocharged $\mathrm{H}_{2} \mathrm{ICE}$ with charge cooling proposed here deliver very high efficiencies running at I 52 to I 54 with a power density even higher than naturally aspirated homogeneous combustion stoichiometric gasoline engines.

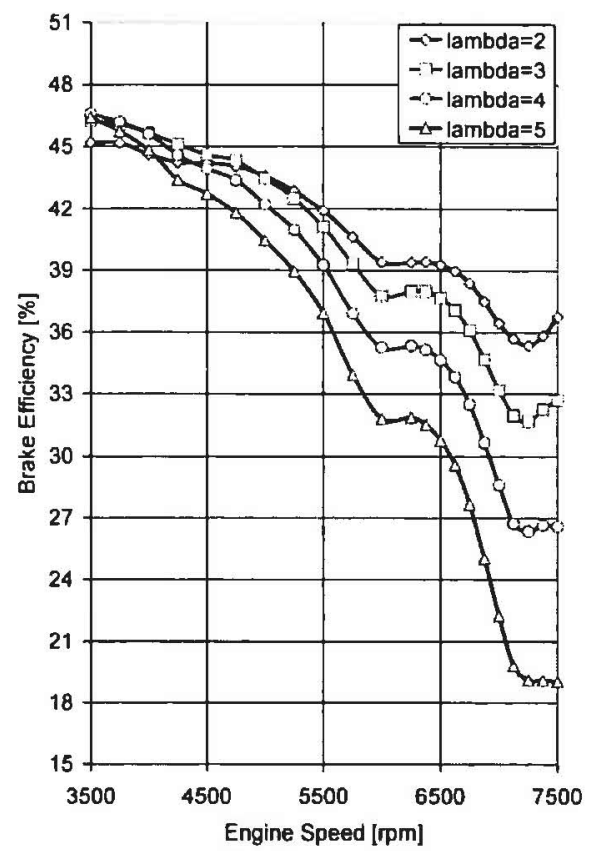

Fig. 8 Brake efficiency results with I $52,3,4$, and 5 at WOT and MBT or knock-limited spark timing

\section{F Authors 2010}

\section{REFERENCES}

1 White, C. A technical review of hydrogen-fueled internal combustion engines. In Proceedings of the Califomia Air Resources Board ZEV Technology Symposium, Sacramento, California, USA, 26 September 2006, available from http $/ / w w w . a r b . c ~ a$. gov/msprog/zevpr og/symposium/pre sentations/ whitepdf.

2 White, C. M., Steeper, R. R., and Lutz, A. E The hydrogen-fuelled intemal combustion engine: a technical review. Int. I Hydrogen Energy, 2006, 31, 1292-1305.

3 White, C., Oefelein, J, and Siebers, D. Sandia hydrogen fueled internal combustion engine program. In Proceedings of the National Science Foundation Workshop on Research Frontiers for Combustion in the Hydrogen Economy, Arlington, Virginia, USA, 9-10 March 2006, available from http $J /$ mechseil linois.edu/rese rch/glumac/NSFW/ whitepdf.

4 College of the Desert, Module 1: hydrogen properties, December 2001, available from http//www1. EereEnergy.Gov/ Hydrogenandfuelc ells/Tech_ Validation/Pdf'/ Fam01ro.Pdf. 
5 Boretti, A. and Watson, H. Numerical study of a turbocharged, jet ignited, cryogenic, port injected, hydrogen engine SAE paper 2009-01-1425, 2009 also In Hydrogen IC engines 2009, 2009 (SAE International, Warrendale, Pennsylvania).

6 Lemmon, E W., McLinden, M. O., and Friend, D. G. Thermophysical properties of fluid systems. NIST Chemistry WebBook, NIST Standard Reference Database Number 69 (Eds P. I Linstrom and W. G. Mallard), 2008 (National Institute of Standards and Technology, Gaithersburg Maryland, availabe from http//webbook.n ist.gov/chemistr y/ fluid (access date 3 October 2008).

7 European Commission, Research, HyICE Optimization of a hydrogen powered internal combustion engine, 2007, available from http//eceuropa eu/ research/transpo $t /$ projects/arti cle_5027_en.html.

8 European Commission, Research, NICE New inte grated combustion system for future passenger car engines, 2007, available from http:/eceuropa .ew/ research/transpo $\mathrm{rt} / \mathrm{projects} /$ arti cle 5054_en.html .

9 Lumsden, G. Watson, H. C., Gasson, N., Chow, C., and Chalko, T. Observations of hydrogen assisted jet ignition. In Proceedings of Hydrogen Power - Theoretical and Engineering Solutions International Symposium (HyPOTHESIS), Gaeta, Italy, June 1995, vol.1, pp. 433-443 (International Association for Hydrogen Energy, Miami, Forida).

10 Lumsden, G. and Watson, H. C. Optimum control of an S.I. engine with a lambda 55 capability. SAE paper 950689, 1995.

11 Lumsden, G. and Watson, H. C. HAJ operation in a hydrogen-only mode for emission control at cold start. SAE paper 950412, 1995.

12 Dober, G. Geometric control of $\mathrm{HC}$ enisions. PhD Thesis, University of Mebourne Parkville, Mebourne, Australia, 2002.

13 Hamori, F. and Watson, H. C. Hydrogen assisted jet ignition for the hydrogen fuelled $\mathrm{SI}$ engine. In Proceedings of the 16th World Hydrogen Energy Conference (WHEC 2006), Lyon, France, 13-16 une 2006.

14 Hamori, F. Optimising the application of HAJ to the supercharged engine. PhD Thesis, University of Melbourne Parkville, Melboume, Australia, 2006.

15 Boretti, A. A. Brear, M. L and Watson, H. C. Experimental and numerical study of a hydrogen fuelled IC engine fitted with the hydrogen assisted jet ignition system. In Proceedings of the 16th Aus tralasian Fluid Mechanics Conference (16 AFMC), Gold Coast, Queensland, Australia, 3-7 December 2007. pp. 1142-1147 (University of Queensland, Brisbane).

16 Mehrani, P. Predicting knock in a HAJ engine. PhD Thesis, University of Mebourne, Parkville, Melbourne, Australia, 2008.

17 Boretti, A. A. and Watson, H. C. Enhanced combustion by jet ignition in a turbocharged cryogenic port fuel injected hydrogen engine. Int. \& Hydrogen Energy, 2009, 34, 2511-2516.
18 Boretti, A. and Watson, H. C. Lean bum direct injection jet ignition internal combustion engine. IP Aust. Provisional Pat. Applic. SPE-11865853 (2009901639), 17 April 2009.

19 Boretti, A. and Watson, H. C. Leen burn direct injection jet ignition internal combustion engine without spark plug. IP Aust. Provisional Pat. Applic. SPEP-11928154 (2009901961), 5 May 2009.

20 Series of NGK racing spark plugs, 2009, available from http//www.ngksp arkplugs.com/ima ges/pdfs' racing_catalog.p df.

21 Delphi Powertrain Systems, Dejphi Multec H 10 GD multi-hole fue injector, 2007, available from http:/delphi.co m/shared/pdf/ppd / pwrtm/gas_ multeodig_hom.pd $f$.

22 Delphi Powertrain Systems, Delphi Multec H20 GD fast single coil fuel injector, 2009, available from http//delphi.co m/shared/pdf/ppd / pwrtm/gas multec_gdifsc.pd $f$.

23 VDO Automotive $A G$, Mobility and nature in harmony, Inteligent, environment-frie ndly powetrain concepts made by Continental, April 2008, availabe from http//www.vdo.c om/NR/rdonlyres/ 4AE2AE7D-EIA1-4D 8C-B5C8-5BAD75A5 B1CD/0/ PT_Bro_EN_Final_160408.pdf.

24 Germma Technologies, GT-Powe, the industry standard, 2009, available from http://www.gtiso ft. $\mathrm{com} / \mathrm{img} / \mathrm{broch} / \mathrm{br}$ och_gtpower.pdf.

25 Boretti, A. A. and Watson, H. C. Development of a direct injection high efficiency liquid phase LPC spark ignition engine. In Proceedings of the SAE 2009 International Powertrains, Fuels and Lubricants Meting, Forence, Italy, 15-17 June 2009, SAE paper 2009-01-18B1 (SAE International, Warrendale Pennsylvania)

26 Boretti, A. A. and Watson, H. C. Development of a direct injection high flexibility CNGLPG spark ignition engine In Proceedings of the SAE 2009 International Powertrains, Fuels and Lubricants Meeting. Florence, Italy, 15-17 tune 2009, SAE paper 2009-01-1969 (SAE International, Wartendale, Pennsylvania).

27 Boretti, A. A. and Watson, H. C. The lean burn < direct-injection jet-ignition turbocharged liquid phase LPG engine In Proceedings of the 15th Asia Pacific Automotive Engineering Conference (APAC15), Hanoi, Vietnam, 26-28 October 2009 (State Publisher, Hanoi).

28 Boretti, A. A. and Watson, H. C. The lean burn direct-injection jet-ignition flexi gasfue LPGICNG engine In Proceedings of the 2009 SAE Powertrains, Fuels and Lubricants Meeting, San Antonio, Texas, USA, November 2009, SAE paper 09FFL0037 (SAE International, Warrendale, Pennsylvania).

29 Boretti, A. A. and Watson, H. C. Comparison of PFi and DI super bike engines. In Proceedings of the 2008 SAE Motor Sports Engineering Conference, Concord, North Carolina, USA, December 200B, SAE paper 2008-01-2943 (SAE Intenational, Warrendale, Pennsylvania). 